\section{Cureus}

\title{
Adult Small Bowel Intussusception and Resolution Captured on Pelvic Ultrasound
}

\author{
Neil P. Larson ${ }^{1}$, Michael J. Yoo ${ }^{1}$, Rachel E. Bridwell ${ }^{1}$ \\ 1. Emergency Medicine, Brooke Army Medical Center, Fort Sam Houston, USA \\ $\square$ Corresponding author: Neil P. Larson, neilplarson@gmail.com \\ Disclosures can be found in Additional Information at the end of the article
}

\section{Abstract}

While abdominal pain is one of the leading causes for ED visits, intestinal intussusception is an infrequent etiology in adults. We present the case of a 22-year-old woman with five days of left lower quadrant abdominal pain with initial workup investigating for a genitourinary source utilizing pelvic ultrasound which revealed small bowel-small bowel intussusception. During the study, resolution of the intussusception correlated temporally with the patient's symptoms. Transient small bowel intussusception in adults has been previously described; however, direct visualization of both the intussusception and its resolution on pelvic ultrasound has not been previously published.

Categories: Gastroenterology, Emergency Medicine

Keywords: adult intussusception, abdominal pain

\section{Introduction}

Abdominal pain is one of the most common chief complaints seen in the ED, accounting for approximately $5 \%$ of all chief complaints [1]. In a young woman of childbearing age, this differential diagnosis is extremely broad. Intussusception, or telescoping of one bowel segment into another, is an infrequent etiology of abdominal pain in adults, with only $5 \%$ of all intussusceptions diagnosed in the adult population [2]. While the majority of large bowel intussusception lead points are malignant in nature, those involving the small bowel are often more benign [3]. Though malignant lesions still compose up to 30\% of small bowel intussusception lead points, other recognized sources include lipomas, adenomas, and neurofibromas among others [2, 4]. However, up to $20 \%$ of adult intussusceptions are idiopathic without identified lead points, with higher incidence occurring in the small bowel [2]. Transient, nonobstructing small bowel-small bowel intussusceptions may also be seen in symptomatic patients during diagnostic imaging, and are more likely idiopathic in nature without long-term clinical sequelae [3-6].

Received 08/30/2019

Review began 08/30/2019 Review ended 09/02/2019 Published 09/11/2019

\section{(C) Copyright 2019}

Larson et al. This is an open access article distributed under the terms of the Creative Commons Attribution License CC-BY 3.0., which permits unrestricted use, distribution, and reproduction in any medium, provided the original author and source are credited.

\section{Case Presentation}

A 22-year-old woman with a past medical history of pelvic inflammatory disease (PID) presented to the ED with a five-day duration of crampy, left lower quadrant abdominal pain associated with nausea and three episodes of nonbloody diarrhea. On review of systems, the patient endorsed new vaginal discharge over these five days.

On arrival to the ED, the patient's vital signs were a blood pressure of $128 / 82 \mathrm{mmHg}$, heart rate of 96 beats per minute, respiratory rate of 16 breaths per minute, pulse oximetry of $100 \%$ on room air, and oral temperature of $98.5^{\circ}$ Fahrenheit with reported pain level of seven on a scale of one to ten. Her physical exam was pertinent for mild tenderness to palpation of the abdomen in her left lower quadrant but without guarding, rigidity, or rebound tenderness. A pelvic exam 


\section{Cureus}

revealed mild left adnexal tenderness and mild cervical motion tenderness. Laboratory studies to include a complete blood count, complete metabolic panel, lipase, qualitative urine pregnancy, urinalysis, potassium hydroxide smear, wet smear, and gonorrhea and chlamydia tests were completed, all with unactionable results. A pelvic ultrasound study with transabdominal and transvaginal approaches was ordered for further investigation. The transabdominal images of the left adnexa revealed a small bowel-small bowel intussusception, which resolved upon study completion (Figure 1). The patient returned from her ultrasound study reporting resolution of her pain and nausea. A repeat physical exam demonstrated interval resolution of her left lower quadrant tenderness. The patient was subsequently discharged with strict ED return precautions and instructions to follow up with her primary care physician. She did not return to the ED within the next seven days.

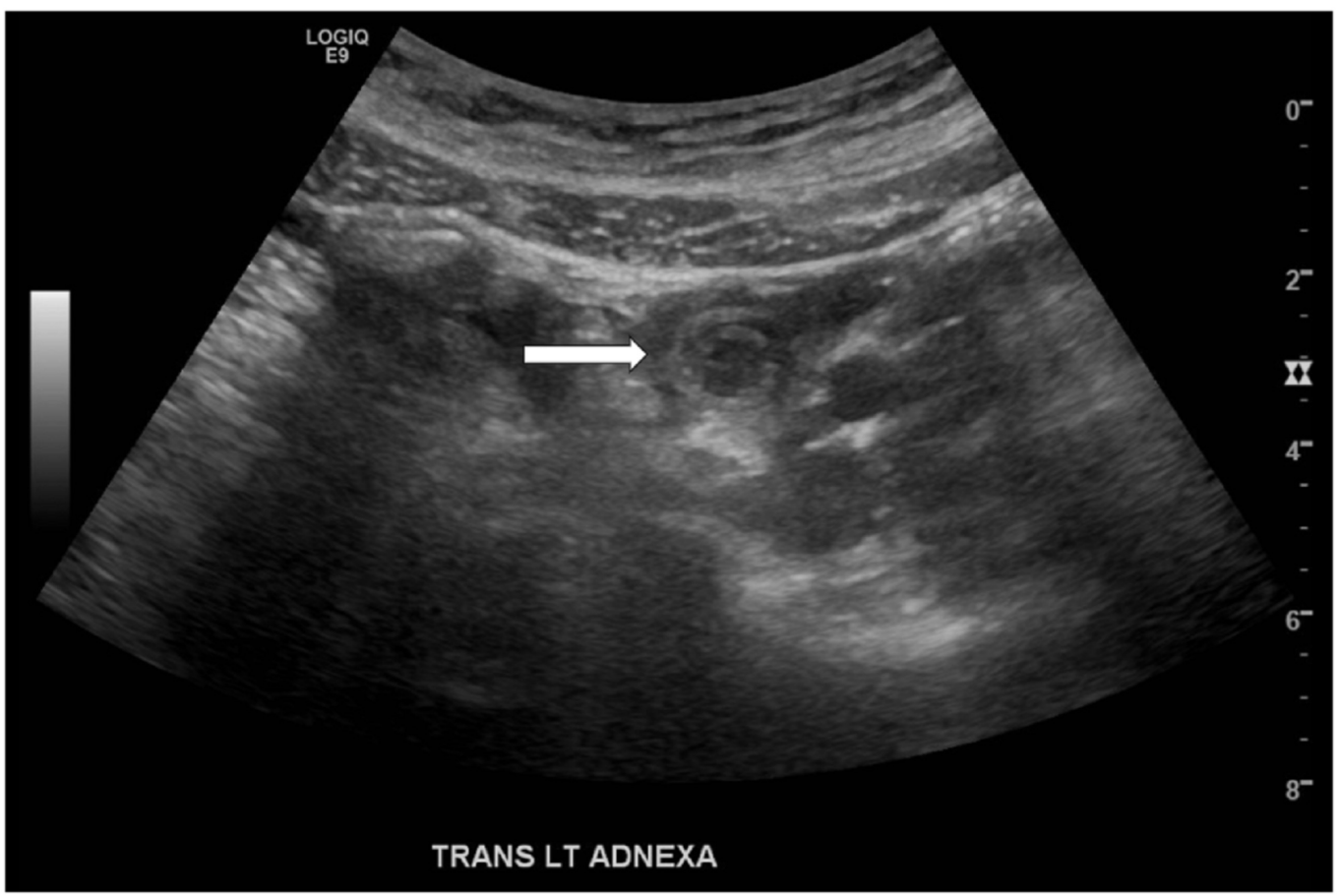

FIGURE 1: Transverse view of transabdominal pelvic ultrasound of the left adnexa revealing targetoid lesion of intussuscepted small bowel (white arrow).

\section{Discussion}

Transient small bowel intussusception has rarely been described in the literature [3-6]. Risk factors for transient small bowel intussusception include Crohn's and celiac disease. However, many patients develop the condition without any known risk factors [3-6]. Though not a known risk factor for intussusception, active and resolved PID have both been associated with development of small bowel obstruction, thought to be caused by translocation of the infection and inflammatory process to the bowel wall and adhesion development, respectively [7-8]. And, both inflammatory processes and adhesions are well recognized sources of small bowel intussusception [2]. However, given our patient's PID was appropriately treated several months prior with negative ED pelvic microbiological testing, active infection and inflammation are less likely. Additionally, a small bowel intussusception due to adhesions would have a low likelihood of spontaneous resolution. Although idiopathic, transient small bowel intussusception has been captured incidentally on imaging performed in asymptomatic patients, the majority of symptomatic patients presented with nonspecific abdominal pain and 
without identification of a lead point [3-6, 9]. However, no publication to date has recorded resolution of symptoms with real-time resolution of the intussuscepted bowel diagnosed on pelvic ultrasound.

In the majority of cases referenced above, patients were diagnosed with CT of the abdomen, with reported accuracy ranging from $58 \%$ to $100 \%$ for diagnosing intussusception [2]. Abdominal ultrasound, the primary radiographic study for diagnosing intussusception in children, has been utilized to a lesser degree in adult diagnosis, likely due to reported accuracy estimates of approximately 50\% [10]. This estimate is likely reflective of baseline operator skill, patient obesity, and gas-filled loops of distended bowel which may obscure diagnosis [2]. In this case, the pelvic ultrasound was obtained in our adult female patient due to initial suspicion for gynecologic pathology, where the transabdominal approach revealed the small bowel-small bowel intussusception and subsequent resolution. Unfortunately, the segments of intussuscepted small bowel were not specified, likely due to gynecologic focus of exam and prompt intussusception resolution.

Transient small bowel-small bowel intussusception may resolve spontaneously. The correlation with documentation of intussusception resolution coinciding temporally with resolution of symptoms after radiographic study completion in the ED has not been previously described in the literature. One case, reported resolution of patient symptoms shortly after radiocontrast small bowel follow through performed the day following symptom onset [4]. Though not an ideal radiographic study, no lead point was identified on the pelvic ultrasound, and with symptom resolution, no further workup was pursued. Surgical exploration is an option utilized for refractory symptoms; bowel reduction due to persistent obstruction; and those at high risk for malignancy. However, there are no formal guidelines for surgical exploration for idiopathic, transient small bowel intussusception. Moreover, while larger small bowel intussusceptions are more likely to require surgical intervention, those measuring less than $3.5 \mathrm{~cm}$ in length are more likely self-limiting [11]. As such, in a low risk patient population, authors advocate for nonoperative treatment with symptom management and close follow up [4, 6].

\section{Conclusions}

Intussusception is a rare but potentially serious etiology of abdominal pain in adults. Idiopathic, transient small bowel-small bowel intussusception is a scarcely reported phenomenon, usually diagnosed on CT scan of the abdomen. Here, we described a case of a nonpregnant, 22-year-old female with left lower quadrant pain, diagnosed with idiopathic, transient small bowel-small bowel intussusception on transabdominal pelvic ultrasound. Intussusception resolution occurred during the study with subsequent symptom and physical exam finding resolution, and the patient was uneventfully discharged without subsequent return to the ED.

\section{Additional Information Disclosures}

Human subjects: Consent was obtained by all participants in this study. Conflicts of interest: In compliance with the ICMJE uniform disclosure form, all authors declare the following:

Payment/services info: All authors have declared that no financial support was received from any organization for the submitted work. Financial relationships: All authors have declared that they have no financial relationships at present or within the previous three years with any organizations that might have an interest in the submitted work. Other relationships: All authors have declared that there are no other relationships or activities that could appear to have influenced the submitted work. 


\section{Acknowledgements}

This manuscript did not utilize any grants or funding. This case report will not be published elsewhere in the same form, in English or in any other language, including electronically without the written consent of the copyrightholder. This manuscript does not reflect the views or opinions of the U.S. government, Department of Defense, U.S. Army, U.S. Air Force, Brooke Army Medical Center, or SAUSHEC EM Residency Program.

\section{References}

1. Kamin RA, Nowicki TA, Courtney DS, Powers RD: Pearls and pitfalls in the emergency department evaluation of abdominal pain. Emerg Med Clin North Am. 2003, 21:61-72. 10.1016/S0733-8627(02)00080-9

2. Marinis A, Yiallourou A, Samanides L, Dafnios N, Anastasopoulos G, Vassiliou I, Theodosopoulos T: Intussusception of the bowel in adults: a review . World J Gastroenterol. 2009, 15:407-411. 10.3748/wjg.15.407

3. Aref H, Nawawi A, Altaf A, Aljiffry M: Transient small bowel intussusception in an adult: case report with intraoperative video and literature review. BMC Surg. 2015, 15:36. 10.1186/s12893-015-0020-6

4. Mehta RS: Jejunal intussusception as an unusual cause of abdominal pain in an adult . Mcgill J Med. 2009, 12:28-30.

5. Lai J, Ramai D, Murphy T, Kasher F: Transient adult jejunojejunal intussusception: a case of conservative management vs. surgery. Gastroenterol Res. 2017, 10:369-371. 10.14740/gr881w

6. Lyons D, Sidhu S: Missed case of intussusception, a rare cause of abdominal pain in adults: A case report emphasizing the imaging findings and review of the literature. Radiol Case Rep. 2019, 14:906-910. 10.1016/j.radcr.2019.05.007

7. Harel Z, Tracy Jr TF, Bussey III JG: Small bowel obstruction in an adolescent with pelvic inflammatory disease due to Chlamydia trachomatis. J Pediatr Adoles Gynecol. 2003, 16:125128. 10.1016/S1083-3188(03)00041-X

8. Al-Ghassab RA, Tanveer S, Al-Lababidi NH, Zakaria HM, Al-Mulhim AA: Adhesive small bowel obstruction due to pelvic inflammatory disease: a case report. Saudi J Med Med Sci. 2018, 6:40.10.4103/sjmms.sjmms_10_17

9. Catalano O: Transient small bowel intussusception: CT findings in adults . Br J Radiol. 1997, 70:805-808. 10.1259/bjr.70.836.9486044

10. Honjo H, Mike M, Kusanagi H, Kano N: Adult intussusception: a retrospective review. World J Surg. 2015, 39:134-138. 10.1007/s00268-014-2759-9

11. Lvoff N, Breiman RS, Coakley FV, Lu Y, Warren RS: Distinguishing features of self-limiting adult small-bowel intussusception identified at CT. Radiology. 2003, 227:68-72. 10.1148/radiol.2272020455 